\title{
O amante japonês, de Armando Silva Carvalho: sobrevivência ou desaparecimento dos vaga-lumes?
}

\author{
Luis Maffei*
}

\section{RESUMO}

\begin{abstract}
Em 2008, Armando Silva Carvalho publicou um livro intitulado O amante japonês, que encena uma relação cheia de afeto entre um indivíduo e um veículo automotivo. Partindo dessa premissa, os poemas, dotados de alta coesão, problematizam diversas questões fortes em nossa contemporaneidade, como o trato do humano com a máquina e a vigência, em nossas sociedades, da mercadoria como item inexorável e que, cada vez mais, exige uma reflexão em estado de abertura. No mesmo ano de 2008, Georges Didi-Huberman editou Sobrevivência dos vaga-lumes, ensaio no qual reflete acerca das possibilidades de perda ou manutenção de zonas inteligentes de afeto em nosso tempo. Este ensaio propõe-se a ler a obra de Armando Silva Carvalho tendo o texto de Didi-Huberman como interlocutor privilegiado.

Palavras-chave: Armando Silva Carvalho. Poesia portuguesa. Corpo x máquina. Georges Didi-Huberman. Contemporaneidade.
\end{abstract}

Em resenha a $\mathbf{O}$ amante japonês, livro de Armando Silva Carvalho editado em 2008, Fernando J. B. Martinho verifica, para além de um jogo com expectativas a serem frustradas, a ironia como estratégia fundamental na elaboração do conjunto de poemas. $\mathrm{O}$ amante japonês do título é, de fato, algo que escorrega ao que um suposto leitor pode esperar, em se tratando especialmente de um livro de poesia. Alguém mais ou menos culto pode ser levado a pensar em Hiroshima, mon amour (1959), filme de Alain Resnais, ou nalguma produção que encene um caso amoroso entre ocidental e oriental. Mas o amante em causa é um automóvel, não um indivíduo.

Interessa-me pensar, a partir disso, na fina tensão que se coloca: a ironia, figura dada a gestos rebeldes, encontra-se na raiz da decepção, pois leva o sintagma a jamais recuperar uma estabilidade comunicativa previsível. Essa ironia está a serviço de uma revisão do que se entende como amor e "amante", portanto tem mesmo vocação rebelde. Por outro lado, amar um carro, numa sociedade tão rigorosamente capaz de misturar consumo e afeto numa rede indiferenciadora,

Universidade Federal Fluminense - UFF. 
tem aspecto, nalguma medida, previsível. E moderno, claro, pois um conjunto de poemas portugueses que passam pela relação de um homem com um veículo automotivo necessariamente lembram o Álvaro de Campos que escreveu "Ao volante do Chevrolet pela estrada de Sintra". Campos, sem dúvida, é o poeta que, no auge do modernismo português, leitor atento de Cesário Verde e afim ao autor d' "O sentimento dum ocidental", mais problematiza uma sociedade na qual o capitalismo já dava cartas, irreversivelmente. Um dos problemas de Campos é enunciado com a palavra liberdade: "O automóvel, que parecia há pouco dar-me liberdade,/ É agora uma coisa onde estou fechado" (PESSOA, 2013, p. 313).

No mesmo ano de 2008, Georges Didi-Huberman edita um livro intitulado Sobrevivência dos vaga-lumes, cujo pretexto é a detecção de Pasolini, nos anos de 1970, de que os vaga-lumes tinham desaparecido. Segundo o pensador francês, a

\begin{abstract}
"dança dos vaga-lumes", esse momento de graça que resiste ao mundo do terror, é o que existe de mais fugaz, de mais frágil. Mas Pasolini, seguido nisso por inúmeros de seus comentadores, foi bem mais longe: ele praticamente teorizou ou afirmou, como uma tese histórica, o desaparecimento dos vaga-lumes. (DIDIHUBERMAN, 2011, p. 25 - destaques do autor).
\end{abstract}

A questão que se levanta aqui pode ser proposta do seguinte modo: $\mathbf{O}$ amante japonês, tendo como companheiro de leitura o texto de Didi-Huberman, apontará para o mesmo "desaparecimento dos vaga-lumes" ou para o que o filósofo propõe, já no título de seu livro, como a sobrevivência dos vaga-lumes? Recuperando palavra-chave de Campos, a liberdade é, no começo do século seguinte às experiências pessoanas, ainda mais restrita ou se veem zonas de exploração para a liberdade no carro de Armando?

A partir de Pier Paolo Pasolini, Didi-Huberman afirma:

Quando a noite é mais profunda, somos capazes de captar o mínimo clarão, e é a própria expiração da luz que nos é ainda mais visível em seu rastro, ainda que tênue. Não, os vaga-lumes desapareceram na ofuscante claridade dos "ferozes" projetores: projetores dos mirantes, dos shows políticos, dos estádios de futebol, dos palcos de televisão. Quanto às singulares engenhocas que se lançam umas contra as outras, não são mais do que corpos superexpostos, com seus estereótipos do desejo, que se confrontam em plena luz dos sitcoms, bem distantes dos discretos, dos hesitantes, dos inocentes vaga-lumes, essas "lembranças um tanto pungentes do passado." (DIDI-HUBERMAN, 2011, p. 31 - destaques do autor). 
Um problema fundamental é o da transformação de tudo em mercadoria, inclusive o vazio e a superexposição. Se tudo está à luz, nada pode ocupar qualquer zona de sombra, zona discreta, visível em sua natureza gris, quase negra. Os "vagalumes desapareceram nessa época de ditadura industrial e consumista em que cada um acaba se exibindo como se fosse uma mercadoria em sua vitrine, uma forma justamente de não aparecer". (DIDI-HUBERMAN, 2011, p. 37-38 - destaques do autor). Penso nisso quando leio o quinto poema de $\mathbf{O}$ amante japonês:

Há muito que não sei levar-te ao mundo. Pareço aquele amante Que não quer exibir uma conquista gasta.

Não sei depois despir-te. Esse guarda-roupa que foi belo,

Falado e invejado,

Oculta a indignação do pobre amarrotado

Que visita os meus sonhos.

Tu dantes sustentavas-me. Agora quem nos vê não sabe

Quem sustenta quem.

Arrebatado por ti às apaixonadas manchetes desportivas

Sou um clube que baixa de divisão

E é apontado a dedo pelos seus mais fiéis adeptos.

Obrigas-me a mudar de camisa como quem muda de alma.

A mudar de rua como quem muda de família.

Perdeste-me os óculos de um sol precoce na ilusão da cegueira

E numa praia sem luz deixaste-me exposto a mim próprio

À sombra da vergonha

Que chegou tarde e não desaparece.

(CARVALHO, 2008, p. 13).

Mundo, lugar das relações e da exibição. O constrangimento do sujeito lírico sugere que, na superexposição a que é submetido, não basta estar oculto numa mercadoria importada, pois a velocidade das mercadorias é tão intensa quanto ilegível: "exposto" a si "próprio" está o eu lírico, pois a luz tanta cega quem o pode ver, mas, pelo contrário, a inevitável surpresa da autoimagem não se neutraliza. O jogo se faz imbricado pela ironia e pelas incompletudes de sentido. Giorgio Agamben é outro convidado de honra em Sobrevivência dos vaga-lumes; ali, entre tantas citações, uma a $\mathbf{O}$ que é o contemporâneo: a "poesia" "é a arte de fraturar a linguagem, de quebrar as aparências, de desunir a unidade do tempo". (AGAMBEM apud DIDI-HUBERMAN, 2011, p. 70). Se assim, talvez seja tarefa redutora responder à pergunta que figura no título deste ensaio, pois a fratura da linguagem de Armando leva o poema a forçar uma identificação entre o corpo amante e o corpo mecânico, numa delirada continuidade que é, a todos os títulos, descontínua, mas não chega ao flagrantemente doentio que se vê em diversas abordagens da relação entre corpo humano e máquina. 
Uma delas foi feita pelo crítico Chaplin de Tempos modernos (1936), ainda na década de 1930. Ali, num mundo já entrevisto por Álvaro de Campos, quando o capitalismo industrial começava a ganhar contornos de entidade difícil de ser confrontada, a máquina engole o homem - que é, aliás, homem histórico, pois operário - e o devolve modificado, talvez perdido enquanto homem e viável apenas enquanto operário. Outra, bem mais recente, é a adaptação de um romance de J.G. Ballard feita por David Cronenberg. Em Crash (2004), o gosto por uma sexualidade estimulada sobretudo por acidentes automobilísticos guarda uma mistura radical entre o corpo que sofre o acidente e seu invólucro veicular, fazendo com que a substância de um corpo invada outro e reconfigure-o, forjando um corpo diferente, híbrido, no limite mesmo da configuração humana.

Não é o que ocorre no poema. As exigências que se supõe estabelecidas ao sujeito que canta o automóvel lembram, em primeiro lugar, outro Álvaro de Campos, o que se quis máquina crendo que a moderna diferença entre máquina e homem levava a relação a quimeras benfazejas - a "Ode triunfal" tem versos muito famosos, tais como:
Ah, poder exprimir-me todo como um motor se exprime!
Ser completo como uma máquina!
Poder ir na vida triunfante como um automóvel último-modelo!
Poder ao menos penetrar-me fisicamente de tudo isto,
Rasgar-me todo, abrir-me completamente, tornar-me passento
A todos os perfumes de óleos e calores e carvões
Desta flora estupenda, negra, artificial e insaciável!
(PESSOA, 2013, p. 79).

A máquina é, nessa futurista perspectiva, materialização de uma completude que ao ser humano é vedada. No entanto, apesar da vontade do sujeito de ser rasgado, penetrado e aberto - vontade de teor masoquista que beira o suicida, como o próprio poema indicará algures -, há algo que o afasta da máquina: para além do verso final “Ah não ser eu toda a gente e toda a parte!”(PESSOA, 2013, p. 86), que dá ao texto um sabor de fracasso conclusivo após toda a euforia de centenas de versos, o fragmento citado tem no "como" um elemento fundamental. Isso assinala a talvez invencível distância que separa o homem do "motor", da "máquina", do "automóvel”, pois o "como", tal um muro que mais afasta que fronteiriça, impõe a comparação apenas porque comparante e comparado são tão distintos que comparáveis - essa é das mais profícuas lições deixadas por Alberto Caeiro.

Num mundo de mercado e valores financiáveis, "Sou um clube que baixa de divisão/ E é apontado a dedo pelos seus mais fiéis adeptos": que jogo se joga? 
Ainda a competição do capital, num nível talvez inimaginável para Pessoa e seus outros nomes, já se falava alto no memorável "Poema em linha reta": "Nunca conheci quem tivesse levado porrada./ Todos os meus conhecidos têm sido campeões em tudo". (PESSOA, 2013, p. 234). Campeões em quê? Na luta que é a sociedade capitalista, competitiva por excelência. O poeta, sofrível competidor, é "vil, literalmente vil" (PESSOA, 2013, p. 235), ou seja, tem valor de mercado, stricto sensu, acentuadamente baixo. No século seguinte, com pouco direito a uma sombra que o livre de estar dentro de um discursivo automóvel, não aparecendo ao se situar num aparecente objeto de consumo e desejo, obrigado ao que DidiHuberman (2011) chamou de "ofuscante claridade dos "ferozes' projetores" e entendendo ainda, como o Campos na estrada, que o carro é um "símbolo" (PESSOA, 2013, p. 312), o poeta é rebaixado, ou seja, feito baixo, feito, lato sensu, vil.

E em meio a isso, a ironia que se imiscui por um discurso de matiz amoroso. Inúmeros versos camonianos servem de mote para muita poesia portuguesa feita em séculos posteriores. Um deles, de matriz platônica-petrarquista, é "Transforma-se o amador na cousa amada". (CAMÕES, 2005, p. 126). Se os ecos dessa transformação, feita erótica em Campos (já o era, aliás, em Camões), não se concretizam, contudo, no heterônimo pessoano mais deflagradamente sensacionista, visões de uma transformação situada numa continuidade física entre corpo e máquina cheia não apenas de sensualidade, mas de potência, quer-se esgarçar n'O amante japonês. Um poema do livro, nesse aspecto, é notável:

Viajou sempre entre nós o riso agudo dos cínicos.

Houve palácios de palavras no ar ao nível do volante

Ou então uma perna de seda, umas calças eróticas

Nas maiores noites de glória da mão que te controla a força.

E sempre esse mau ciúme do teu génio

Em baixo, numa segunda instância

Das mudanças do sexo.

(CARVALHO, 2008, p. 10).

Há sucessivas combinações sugestivamente sexuais; "a mão que te controla a força", por exemplo, dá cor a uma cena de manipulação entre amantes, tendo "a mão", substantivo feminino, a ação do controle, e o tu ganhando a masculinidade da "força". Mas uma "segunda instância" é a das "mudanças do sexo", o que sugere o jogo ser fraturado entre as manobras da direção do veículo, a caixa de marcha e suas mudanças, e os efeitos de erotismo que isso pode ter. $\mathrm{O}$ jogo, para usar ideia de Fernando J. B. Martinho, é deceptivo, pois muito do que se insinua é 
sexual para que, no limite, o sexo não se faça. Amar o objeto - já dirá “o riso agudo dos cínicos"? - é, pela impossibilidade de haver entrada erótica entre os corpos, a representação de um absurdo, e, quase numa interpretação da famosa assertiva lacaniana, fica explícito o não-haver dessa relação sexual.

O liame entre cultura e mercadoria é já um lugar-comum em diversas reflexões. Assim Didi-Huberman comenta a versão de Pasolini para essa evidência:

Os vaga-lumes desapareceram, isto quer dizer: a cultura, em que Pasolini reconhecia, até então, uma prática-popular ou vanguardista - de resistência tornou-se ela própria um instrumento da barbárie totalitária, uma vez que se encontra atualmente confinada no reino mercantil, prostitucional, da tolerância generalizada. (DIDIHUBERMAN, 2011, p. 41 - destaques do autor).

Não perco de vista que o drama amoroso performatizado entre um eu e um tu nos poemas de Armando Silva Carvalho se dá entre um humano, situado na língua, e um automóvel, situado, para dialogar com Pasolini e Didi-Huberman, no "reino mercantil". $\mathrm{O}$ amante japonês não é uma personagem vivida por Eiji Okada, mas um bem de consumo, e conferir a isso um valor não seria praticar o fetiche da mercadoria num nível imprevisto por Marx? Ainda que arriscadamente redutora, não fujo ao bojo da pergunta que baliza o título deste experimento que ora faço: se o carro está confinado ao mundo da "tolerância generalizada", posto que é um entre tantos, e tem como critérios para aferição de seu valor simbólico os mesmos que organizam majoritariamente a simbologia do chamado mercado, além de suas consecutivas interpretações, $\mathbf{O}$ amante japonês é, portanto, indício do desaparecimento dos vaga-lumes?

$\mathrm{Ou}$, por outro lado, a dança amorosa que aponta para a desaparição de pequenos brilhos, reais, potentes como a literatura menor para Deleuze e Guattari (1977), em virtude de ser dança, já é, ela própria, indicativo da sobrevivência dos vaga-lumes ou, melhor ainda, um vaga-lume em movimento, dono de alguma liberdade? - afinal, se é uma impossibilitadora diferença que apresenta o infactível amoroso n'O amante japonês, é a um semelhante, também situado na língua, que o poeta oferece seu suposto brilho. Segundo Didi-Huberman, os "vaga-lumes se apresentam a seus congêneres por uma espécie de gesto mímico que tem a particularidade extraordinária de ser apenas um traço de luz intermitente, um sinal, um gesto" (DIDI-HUBERMAN, 2011, p. 58 - destaques do autor). Ao convocar Agamben para sua reflexão, o ensaio de 2008 afirma que, no pensamento do autor de Estâncias, vem ao caso "dar-se os meios de ver aparecerem os vaga-lumes no espaço de superexposição, feroz, demasiado luminoso, de nossa história presente. 
Essa tarefa, acrescenta Agamben, pede ao mesmo tempo coragem - virtude política - e poesia". (DIDI-HUBERMAN, 2011, p. 70 - destaques do autor).

O poema para eles possível é esse gesto. O poema possível para poeta e leitores é o poema mesmo. Ao pensar em "barbárie totalitária", o cineasta e poeta italiano e o filósofo francês têm Adorno na bagagem, mas cônscios, como o próprio Adorno, aliás, esteve anos após a declaração famosa, que certos monumentos da barbárie guardam força para ser também denúncias da barbárie, e, nesse sentido, gestos de luta contra a barbárie. Ainda que diversos discursos prestigiosos deste tempo não revelem, o brutal vazio da comunicação maciça, com sua atenção à repetição do mesmo e, especialmente, sua hostilidade ao exercício de pensamento, é cheio de política. A manobra é totalitária não porque orquestrada com planejamento e claras intenções por um malévolo e oculto cérebro, mas porque o resultado dos "ferozes projetores" é mesmo totalitário, dadas a indiferenciação, a "ofuscante claridade" e a elevação do dinheiro a condição divina - nada disso é estranho à reflexão feita até aqui.

Didi-Huberman afirma: "A imaginação é política, eis o que precisa ser levado em consideração". (DIDI-HUBERMAN, 2011, p. 61). Contra a política, portanto, outra política, mas, é evidente, política. Agamben, citado por seu colega francês, aponta, em Infância e história, para o declínio da experiência, citando os turistas que preferem o registro da máquina fotográfica ao olho-experimento. Que tipo de experiência está exposta quando o sujeito lírico de Armando Silva Carvalho experimenta o mundo dentro de outra máquina? "É quase a minha casa que se move", "É quase a minha cama que se move" (CARVALHO, 2008, p. 53), dizem versos dipostos numa mesma página.

O poema, no entanto, é também político - digo o poema porque entendo $\mathbf{O}$ amante japonês como um longo poema único, formado, não obstante, por poemas autonomamente legíveis. Numa quebra da então vigente dinâmica fundada na ironia, lê-se:

Pobre carro de um pobre num país de pobres.

Um cão lento e sem pêlo que vai onde lhe permite o dobrar da pobreza

Forçando a pele da boca contra a resistência

Do açaime.

Até nestas palavras a mais do menos da minha escrita

O teu andar metálico evita o tilintar

Da moeda corrente. És um cantil movido por uivos

E latidos.

(CARVALHO, 2008, p. 63) 
Nessa outra política, o preponderante papel da imaginação, da imagem, da construção estética do gesto imagético. Didi-Huberman divisa

certas dificuldades teóricas com as quais lida Agamben ao manipular, conjuntamente, a historicidade heideggeriana e a imagem dialética benjaminiana, ou ainda o messianismo de São Paulo, com um reflexão sobre a "Solução final" projetada pelos nazistas a respeito do povo judeu. Somente a tradição religiosa promete uma salvação para além de qualquer apocalipse e de qualquer destruição das coisas humanas. As sobrevivências, por sua vez, concernem apenas à imanência do tempo histórico: elas não têm nenhum valor de redenção. (DIDI-HUBERMAN, 2011, p. 82-84 - destaques do autor).

O pensador francês não pensa em redenção, e não vê na sobrevivência dos vaga-lumes, como, afinal, em nenhuma, fato redentor. Vê tempo histórico, este mundo, lugar onde o "pobre" "num país de pobres" tem um "Pobre carro", ou onde isso ecoa noutro poema do livro, que começa com o verso: "Velho carro de um velho num país de velhos" (CARVALHO, 2008, p. 66). É magistral a posição dos componentes do sintagma que abre verso e poema: "Pobre país" pode causar a impressão de que trará consigo algo menos pleno de concretude, ao contrário de sintagma que atendesse à ordem substantivo - adjetivo. Mas o verso é poderosamente crítico de uma realidade localizada num "tempo histórico", e as posições na expressão acabam por criar um desconforto a mais. O poema tem certa memória neorrealista - ocorre-me o Carlos de Oliveira de Mãe pobre (1945), poeta, aliás, com quem Armando dialogará noutro momento d'O amante japonês - , e remete a outros tantos textos em poesia portuguesa dedicados a tematizar o pobre e/ou a pobreza, desde Camões até a poesia mais contemporânea. Remete também ao totalitarismo que espreita ao fundo das identidades nacionais.

Um dos tópicos centrais da reflexão de Didi-Humerman é a imagem, porque a imagem dos vaga-lumes, desde Pasolini, é literal, e por isso tem imensa força de símbolo - esse é um dos motivos por que o ensaio comenta inclusive aspectos biológicos dos insetos que emprestam seu nome ao título do livro - não confundível com o dito por Álvaro de Campos. Disposto a uma " "política das sobrevivências", que "dispensa muito bem - dispensa necessariamente - o fim dos tempos" (DIDIHUBERMAN, 2011, p. 84 - destaques do autor), distinta da confusão que se infiltra no pensamento angambeniano quando cede à tentação redentora, o autor do recente Écorces afirma: “(...) imagem não é horizonte. A imagem nos oferece algo próximo a lampejos (lucciole), o horizonte promete a grande e longínqua luz (luce)." (DIDI-HUBERMAN, 2011, p. 85 - destaques do autor). 
É evidente que essa ideia de imagem nada tem que ver com a exposta por Guy Debord, que localiza na "sociedade do espetáculo" uma desordenação total das imagens que embota possibilidades fartas de sintaxes pensantes. Para DidiHuberman,

A imagem é pouca coisa: resto ou fissura (...). Um acidente do tempo que a torna momentaneamente visível ou legível. Enquanto o horizonte nos promete o todo, constantemente oculto atrás de sua grande "linha" de fuga. "Uma das razões pelas quais eu tenho reservas a respeito de todos os horizontes", escreve Derrida em Force de loi (...), por exemplo, a ideia reguladora kantiana ou o advento messiânico, ao menos em sua interpretação convencional, é que são justamente horizontes. Um horizonte, como seu nome o indica, em grego, é ao mesmo tempo a abertura e o limite da abertura que define ora um progresso infinito, ora uma espera." (DIDI-HUBERMAN, 2011, p. 87 - destaques do autor).

Isso me faz pensar de fato em Écorces, livro no qual o filósofo reflete também sobre imagens a partir de uma visita a Auschwitz. Suponho que as imagens são tão caras a esse autor, que certamente leu atentamente Merleau-Ponty, em virtude do aspecto acidental que elas possuem, de sua recusa ao todo. Mas o aspecto disso que mais me fascina - uso esse verbo com a maior intencionalidade - é o da visibilidade, ou legibilidade, das imagens, algo que o horizonte, "abertura" e "limite da abertura", não permite, segundo Derrida, e não se apresenta no que chamei, lendo Armando, de velocidade das mercadorias. Fascinar: etimologicamente, cativar pela força do olhar. Ser fascinado é, tanto quanto ver, ser visto. Nesse sentido, a imagem é legível como a poesia, ou a literatura em geral que seja eivada de poeticidade, a única que interessa. Legível e legente, para usar termo caro à revolucionária obra de Maria Gabriela Llansol.

Avanço num aspecto importante, pois há uma sutileza poderosa nisso. Debord, nomeado em Sobrevivência dos vaga-lumes, escreveu: “O espetáculo é o capital em tal grau de acumulação que se torna imagem”. (DEBORD, 1997, p. 25). Não é essa imagem, forjada como instrumento anestésico, a que me fascina, entendendo-a como a entende Didi-Huberman. Tampouco se trata de um olhar que nos olha com vigilância e controle. Em O que vemos, o que nos olha, leio:

o túmulo, quando o vejo, me olha até o âmago - e nesse ponto, aliás, ele vem perturbar minha capacidade de vê-lo simplesmente, serenamente - na medida mesmo em que me mostra que perdi esse corpo que ele recolhe em seu fundo. Ele me olha também, é claro, porque impõe em mim a imagem impossível de ver daquilo que me fará o igual e o semelhante desse corpo em meu próprio destino 
futuro de corpo que em breve se esvaziará, jazerá e desaparecerá num volume mais ou menos parecido. Assim, diante da tumba, eu mesmo tombo (...). (DIDI-HUBERMAN, 1998, p. 66).

Certas imagens só são legíveis porque nos olham, como a citada imagem do túmulo. A afetação só existe por esse motivo, já que o horizonte, por exemplo, não devolve olhar algum, e, logo, tem pouco potencial de legibilidade, de visibilidade.

"Pobre carro": eco, imagem, não sei se metáfora, mas certamente um fornecedor de lucciole - não uma lucciola, que fique claro; os lucciole são os que apontam para a sobrevivência, os poemas, e também para seu risco de desaparecimento, num discurso vigoroso e político: "Um cão lento e sem pêlo que vai onde lhe permite o dobrar da pobreza/ Forçando a pele da boca contra a resistência/ Do açaime" são versos que criam mais uma ambivalência, pois dizem do carro e da própria poesia atualizada no livro, especialmente em virtude da expressão "Até nestas palavras". "Um cão lento e sem pêlo", um carro enfiado em poemas; imagens em nada conspiradoras da sociedade do espetáculo, ainda que a acusem, e nada conspiradoras justamente porque a acusam. E não haverá "açaime" que cale o poeta tão "pobre" como Camões, outro que não se calou mesmo cercado por "pobres", paupérrimos ouvidos, e inscreveu sua poética de múltiplas transformações.

Pobreza: a partir da constatação de Benjamin da queda do valor da experiência, em que o uso de expressão advinda da economia é estratégico, Didi-Huberman diz: "O valor da experiência caiu de cotação, sem dúvida. Mas a queda ainda é experiência, ou seja, contestação, em seu próprio movimento, da queda sofrida. A queda, o não saber se tornam potências na escrita que os transmite." (DIDIHUBERMAN, 2011, p. 143). Pode-se articular intensamente a afirmação à experiência que se verifica nos poemas d'O amante japonês: a queda das possibilidades de peculiarização, as constantes escorregadelas pela ironia, uma corajosa fala que, potente, é contestação e fratura:

Alguém predicou a elipse, o paradoxo,

A contradição,

Perguntas sem resposta,

Caminhos, vias, despertares

Meditação, concentração, o ensino das posturas.

Sento-me em ti na posição zazen

Coluna vertebral erguida, cabeça a suportar

O céu do sofrimento,

E os rios do riso correndo a nosso lado, 
Ó automóvel zen.

Um carro sem paixões, com a ambição esgarçada

Nos estofos,

Nas humildes tarefas do transporte,

Alças-me ao instante repentino

$\mathrm{Na}$ senda do satori.

Sem Buda e sem sutras, a laca caligráfica

Escorre dos meus dedos

E uma natureza humilde, disfarçada no preto,

Fica a marcar-me a sorte, a tua matrícula,

Num amor igual e sem limites.

(CARVALHO, 2008, p. 52).

O poema explora o irrealizável nexo entre um carro japonês e certos aspectos religiosos da cultura do extremo oriente, como o budismo. "Sem Buda e sem sutras", o automóvel só é "zen" em mais um gesto irônico do poema, que, no entanto, não tem ironia alguma em sua procura por amor numa caligrafia que não é em kanji, mas tem grande potência expressiva e estética.

A imagem, para Didi-Huberman "algo que se revela capaz de transpor o horizonte das construções totalitárias" (DIDI-HUBERMAN, 1998, p. 118 destaques do autor), exige movimento. O veículo de Armando Silva Carvalho, nesse sentido, é inegável apontamento de movência:

Hoje os olhos são míopes

E eu um assassino dentro do teu corpo.

Há palavras de sangue caídas

Ao meu lado.

Mas sorvo mesmo assim essas imagens densas

Enquanto o esforço sobe o nevoeiro

E tu não te arrependes de me levares contigo

Atraiçoado.

(CARVALHO, 2008, p. 59)

A ambiência é de um crime, que talvez seja, se eu pensar em Herberto Helder, e não o faço casualmente, a própria realização do texto, pois o sujeito lírico revela-se "assassino". Nesse sentido, o desvio de uma norma totalitária, prática de subversão, é míope, já que reconhece a ação alteradora do olhar, que "mesmo assim", e por isso mesmo, sorve "imagens densas". O olhar diz-se míope inclusive em virtude do "nevoeiro", marca do "horizonte das construções totalitárias", ambiente de difícil visão, de esforço especial de ver e, como escreveu Pessoa em Mensagem, de prever. 
E de lembrar. Hanna Arendt é citada por Didi-Huberman ao ver um

"tesouro sem idade que, nas circunstâncias mais diversas, aparece bruscamente, de improviso, e desaparece novamente em outras condições misteriosas", nalgum lugar na brecha aberta entre memória e desejo. Seria preciso que a memória fosse "uma força e não um fardo". (DIDI-HUBERMAN, 2011, p. 152-153 - destaques do autor).

Todo poeta é, antes de tudo, leitor. Jamais caindo numa gagueira intertextual, risco que corre todo texto, alguns poemas d'O amante japonês recuperam exemplares da literatura portuguesa e universal, citando, por exemplo, Novalis, o que me parece a assunção de uma vontade romântica trans-histórica que dá inconformidade e inovação à poesia mais arrojada. Garrett, romântico com ganas por vezes clássicas, por vezes revolucionárias, também é convidado, e Drummond, entre outros exemplos. A estrutura da obra, um poema em poemas, guarda nisso e em sua narratividade uma memória épica, ainda mais pela presença do eco, écorce, da viagem marítima, cantada, contada e descontada n'Os Lusíadas. N'O amante japonês, todos os versos de todos os poemas começam com inicial maiúscula, o que insinua ter o livro uma gana clássica, não em virtude de antiguidade, estilo ou importância, mas pelo privilégio de uma memória, "força e não fardo", que permite ao contemporâneo explorar a "brecha aberta entre" ela, a memória, e o "desejo".

Nesse sentido, torna-se forçosa uma reinvenção do desejo, que, exigente de relação, busca também reinventar o automóvel. Móvel, esse desejo, a partir de um olhar que se desvie um pouco do totalitarismo mercantil e privilegie o fato de o desejo imperiosamente existir e exigir atritos, é criativo na refiguração do carro, tornando-o um amante japonês possível ao menos na construção sintagmática.

Um diálogo muito especial no livro é travado com o recém-referido Herberto Helder. O poema herbertiano que Armando Silva Carvalho chama para colóquio assim começa:

Se perguntarem: das artes do mundo?

Das artes do mundo escolho a de ver cometas

despenharem-se

nas grandes massas de águas: depois, as brasas pelos recantos, charcos entre elas.

(HELDER, 2009, p. 494) 
A celebração do movimento humano que baila junto com o movimento do mundo, uma das suas artes, fica assim na versão de Armando:

Das artes do mundo escolho a de ver cometas

A cair no meu tempo.

Longos bordados de luz: histéricos, por não serem mortais

Como o meu corpo,

Baptismais,

Por não serem mais cruéis que meu ofício.

(CARVALHO, 2008, p. 30).

Crueldade, ofício, morte e batismo são palavras-chave em Herberto, para além da conversa direta. Os "cometas" se despenham no autor de Do mundo (2009), e, no de Lisboas (2000), são escolhidos por seu potencial de tempo. Poético, claro, pelas fissuras na cronologia que um poema pode fazer, mas também histórico, tempo que cabe em falas humanas, no qual faz pouco sentido falar em redenção. Não se trata, portanto, de mero intertexto, mas de gesto da memória, forja de uma experiência cujo valor está, muito particularmente, na mobilidade do infinitivo: "a cair", pois, leio em Didi-Huberman, "a queda ainda é experiência".

Sempre se move $\mathbf{O}$ amante japonês, seja na ironia, no discurso amoroso, nos brilhos vagos que dá a ver. Sempre se movem os "vaga-lumes" quando, sobrevivos, só nos dão a notar sua sobrevivência porque nos incutem o risco de seu iminente desaparecimento enquanto caem em nossos olhos deslumbrados, ou caem, simplesmente, movendo uma liberdade irredutível, liberdade até mesmo de tentar a humanização amante de um carro - reapareceu a palavra mais perigosa que Álvaro de Campos grafou em seu poema automobilístico. No encerramento do livro de Armando, é de movimento que o poeta fala, e de uma liberdade que precisa ser conquistada atentamente, cantadamente, liricamente; se a vida camoniana esteve "pelo mundo em pedaços repartida" (CAMÕES, 2005, p. 221), agora "A vida" se acha "em velocidade renascida":

Salve ó corpos móveis, decantados, redimidos

Por uma natureza que clama noutro espaço

A vida em velocidade renascida,

Liberta dos seus óvulos, das suas enfermeiras de origem,

Das suas carpideiras sacras,

Dos primórdios do som, do final

Deste canto lírico.

(CARVALHO, 2008, p. 108) 


\begin{abstract}
In 2008, Armando Silva Carvalho published a book titled O amante japonês, which stages a relationship full of affection between an individual and an automotive vehicle. Starting from this premise, the poems, endowed with high cohesion, deals with various issues strong in our contemporaneity, as the deal of the human with the machine and the duration, in our societies, of the merchandise as inexorable item and that, increasingly, demands na open reflection. In the same year of 2008, Georges Didi-Huberman edited Sobrevivência dos vaga-lumes, essay in which he reflects on the possibilities of loss or maintenance of intelligent areas of affection in our time. This essay proposes to read the work of Armando Silva Carvalho taking the text of Didi-Huberman as a privileged interlocutor.
\end{abstract}

Keywords: Armando Silva Carvalho. Portuguese poetry. Body x machine. Georges Didi-Huberman. Contemporaneity

Referências

CAMÕES, Luís de. Rimas. Edição de Álvaro J. da Costa Pimpão. Coimbra: Almedina, 2005.

CARVALHO, Armando Silva. O amante japonês. Lisboa: Assírio \& Alvim, 2008. CARVALHO, Armando Silva. Lisboas. Lisboa: Ed. Quetazal, 2000.

DEBORD, Guy. A sociedade do espetáculo/ Comentários sobre a sociedade do espetáculo. Tradução de Estela dos Santos Abreu. Rio de Janeiro: Contraponto, 1997.

DELEUZE, G., GUATTARI, F. Kafka: por uma literatura menor. Tradução de Júlio Castañon Guimarães. Rio de Janeiro: Imago, 1977.

DIDI-HUBERMAN, Georges. O que vemos, o que nos olha. Tradução de Paulo Neves. São Paulo: 34, 1998.

DIDI-HUBERMAN, Georges. Sobrevivência dos vaga-lumes. Tradução de Vera Casa Nova \& Márcia Arbex. Belo Horizonte: Editora UFMG, 2011.

HELDER, Herberto. Ofício cantante - poesia completa. Lisboa: Assírio \& Alvim, 2009.

MARTINHO, Fernando J. B. recensão crítica a O amante japonês. Revista Colóquio/Letras. Lisboa: Fundação Calouste Gulbenkian. Disponível em http://co- 
loquio.gulbenkian.pt/bib/sirius.exe/news?i=32. Acesso a 17 de fevereiro de 2013.

PESSOA, Fernando. Poesia completa de Álvaro de Campos. Edição de Teresa Rita Lopes. São Paulo: Companhia das Letras, 2013. 
